\title{
DANIEL Y APOCALIPSIS: SU IMPORTANCIA PARA EL SIGLO XXI
}

[Daniel and Revelation: Its importance for the $21^{\text {st }}$ century]

\author{
Nhilo A. Jaimes y Joel Iparraguirre \\ nhilojaimes@upeu.edu.pe \\ joeliparraguirre@upeu.edu.pe \\ Facultad de Teología \\ Universidad Peruana Unión \\ Lima, Perú
}

Recibido: 20/12/2018

Aceptado: 01/02/2019

\section{Resumen}

Daniel y Apocalipsis son dos libros bíblicos peculiares pues su mensaje eminentemente simbólico, con bestias que salen de la tierra y del mar y enfocado en el fin del mundo, causa temor entre los lectores de hoy. Sin embargo, ¿deberíamos temer a los eventos finales y al fin del mundo, tal como está registrado en estos dos libros proféticos? ¿Será posible encontrar en ellos un mensaje de esperanza? Para responder a estas preguntas, primero veremos cómo Daniel y Apocalipsis moldean 1) nuestra percepción de la historia, 2) nuestro concepto de la existencia y 3) nuestra expectativa del futuro en tres dimensiones: global, eclesiástico y personal.

Palabras clave: Daniel, Apocalipsis, historia, profecía, iglesia, siglo XXI

\begin{abstract}
Daniel and Revelation are two peculiar biblical books because their eminently symbolic message, with beasts coming out of the earth and sea and focused on the end of the world, causes fear among today's readers. However, should we fear the final events and the end of the world as recorded in these two prophetic books? Will it be possible to find in them a message of hope? To answer these questions, we will first look at how Daniel and Revelation shape 1) our perception of history, 2) our concept of existence, and 3) our expectation of the future in three dimensions: global, ecclesiastical, and personal.
\end{abstract}

Keywords: Daniel, Revelation, history, prophecy, church, $21^{\text {st }}$ century 


\section{INTRODUCCIÓN}

En alguna oportunidad todos nos hemos topado con la misma pregunta, ¿qué sucederá con nuestro mundo en el futuro? Hace algunos años, el geofísico británico Bill McGuire afirmó que "el mayor problema con predecir el fin del mundo es que, si resulta ser cierto, no puede existir un gozo en la gloria" ${ }^{1}{ }^{\mathrm{El}}$ terrorífico futuro trazado de esta manera por la ciencia se ha difundido entre la cultura popular de occidente a través de Hollywood en películas tales como Impacto Profundo (1998) y Armageddon (1998), en las que unos cometas se dirigen hacia la tierra causando un cataclismo de efecto devastador a escala mundial. En estas producciones, se muestran olas de altura inimaginable asolando ciudades enteras, mientras que el resto de la humanidad se refugia en cuevas profundas para sobrevivir y algunos astronautas son enviados al espacio para evitar el desastre. De modo similar, el film $2012^{2}$ (2009) presenta un futuro desesperanzadoramente horroroso en el que terremotos, erupciones volcánicas y maremotos acaban con la mayor parte de la humanidad. En un escenario alternativo, pero no menos escalofriante, Terminator y todas sus secuelas (1984, 1991, 2003, 2009, 2015), así como Matrix (1999), demuestran cómo la inteligencia artificial puede volverse contra el mundo amenazando con extinguir la vida humana. ${ }^{3}$

Al asunto de cómo terminará el mundo se añade el interés por cuándo terminará. Respondiendo a esta pregunta, el astrónomo británico Martin Rees dijo: "Pienso que las probabilidades de que nuestra presente civilización sobre la tierra sobreviva más allá de este siglo no superan el cincuenta por ciento". ${ }^{4} \mathrm{~A}$ pesar de este sombrío cuadro de nuestro futuro pintado por la ciencia moderna,

1Bill McGuire, A Guide to the End of the World: Everything You Never Wanted to Know (Oxford: Oxford University Press, 2002), 1.

${ }^{2}$ La expectativa por esta película fue ampliamente influenciada por una masiva campaña por internet pregonando la inminente realización de la profecía maya. Véase Matthew Restall y Amara Solari, 2012 and the End of the World: The Western Roots of the Maya Apocalypse (Lanham, MD: Rowman \& Littlefield, 2011).

3Para un análisis de los escenarios catastróficos mostrados en estas y otras recientes películas del mismo género, véase Peter Szendy, Apocalypse-Cinema: 2012 and Other Ends of the World, trad. Will Bishop (New York: Fordham University Press, 2015).

${ }^{4}$ Martin Rees, Our Final Hour: A Scientist's Warning (New York: Basic Books, 2003), 8. 
y “a pesar de su aparente inevitabilidad, nos rebelamos contra este espantoso destino con todas las fuerzas que podemos reunir". ${ }^{5}$ En estas últimas palabras hay algo que debemos considerar con suma atención. Note esto: cuando tenemos en mente un futuro desastroso, naturalmente nos rebelamos contra él. Dicho de otro modo, nadie se siente a gusto con la idea de un futuro en el que todo, incluyendo su vida y la vida de sus seres queridos, pasará a la historia como un poco de polvo en el cosmos, sin ningún significado más allá de haber participado de una porción diminuta de la dimensión espacio-tiempo de un universo implacable e irracionalmente genocida. Y claro está que, con un futuro así, nuestro presente llega a ser una lucha constante por adquirir un significado para nuestra vida que sea más duradero que los años que nuestro corazón nos mantenga en pie.

Lo que creemos sobre nuestro futuro afecta tanto nuestro presente que "la posibilidad de un cumplimiento futuro - sea firme o ilusorio - es aún la base indispensable para ser y actuar en el presente" ${ }^{6}$ ¿Quiénes somos? ¿cuál es nuestro papel en este mundo? Estas preguntas básicas son respondidas cuando aceptamos alguna visión particular de nuestro futuro. Es en este punto en el que nos incumbe considerar dos libros de las Sagradas Escrituras: Daniel y Apocalipsis. Ambos conforman la mayor parte de la literatura apocalíptica de la Biblia, designación que se refiere en términos generales a un sistema de pensamiento según el que "Dios ha revelado el fin inminente de la continua lucha entre el bien y el mal en la historia". ${ }^{7}$ De este modo, ambos libros presentan una visión del fin y del futuro que difiere radicalmente de la presentada por la ciencia, un futuro en el que se cumplen las promesas divinas, en el que la salvación se

5Paul Halpern, Countdown to Apocalypse: A Scientific Exploration of the End of the World (Cambridge: Perseus, 1998), 38.

${ }^{6} \mathrm{C}$. Bawa Yamba, "Going there and getting there: the future as a legitimating charter for life in present", en Contemporary Futures: Perspectives from Social Anthropology, ed. Sandra Wallman, ASA Monographs 30 (London: Routledge, 1992), 109. Énfasis añadido.

7John J. Collins, ed., Encyclopedia of Apocalypticism I: The Origins of Apocalypticism in Judaism and Christianity (New York: Continuum, 1999), vii. 
ofrece tanto al individuo como al cosmos, y en el que la intervención divina sobrenatural hace nuevas todas las cosas. ${ }^{8}$

Por esta razón, demostrar la importancia de algo esencialmente relevante como el estudio de Daniel y Apocalipsis es un desafío. Se corre un doble riesgo al hacer el intento: por un lado, está el riesgo de no apreciar plenamente su valor, dejando de lado asuntos de extrema importancia por considerarlos poco prácticos; y, por otro lado, está el riesgo de no llegar al corazón del lector al no presentar adecuadamente lo que el mensaje de ambos libros significa realmente para él o ella. Por consiguiente, estos dos aspectos de la importancia, uno objetivo y otro subjetivo, ${ }^{9}$ deben ser tratados por igual a fin de determinar cuánto vale verdaderamente el estudio de Daniel y Apocalipsis hoy.

\section{DANIEL Y APOCALIPSIS: SU IMPORTANCIA UNIVERSAL}

Empecemos con el aspecto objetivo, es decir, con el valor que Daniel y Apocalipsis tienen por sí mismos a nivel universal. Desde muy temprano en nuestra vida, todos aprendemos a identificar el contexto en el que nos encontramos $\mathrm{y}$, muy pronto, nos adaptamos a dicho contexto dentro de nuestra cultura. ${ }^{10}$ Por ejemplo, si usted está en una reunión social, como en un cumpleaños, sabe que su lenguaje y su conducta pueden ser más familiares y directos. $\mathrm{Si}$, por otra parte, está en una cita deportiva, no puede presentarse con saco y corbata. Imagínese qué vergüenza tendría que pasar si no supiera reconocer el contexto en el que se desenvuelve su vida cotidiana. De ser así, la próxima vez que se reúna en un encuentro formal o eclesiástico todos lo verían llegar con un short, sandalias y polo. ¿Raro cierto? Aunque esta capacidad nos 543.

${ }^{8}$ Anthony C. Thiselton, The Hermeneutics of Doctrine (Grand Rapids, MI: Eerdmans, 2007),

${ }^{9}$ Hasta la fecha, la teoría del valor, lo que podríamos llamar la "teoría de la importancia de alguna cosa", ha delineado meticulosamente estos dos aspectos fundamentales a la hora de determinar lo que "es importante". Sobre el aspecto objetivo véase Ralph Barton Perry, General Theory of Value: Its Meaning and Basic Principles Construed in Terms of Interest (Cambridge: Harvard University Press, 1950), 17-22; sobre el aspecto subjetivo véase Gerald F. Gaus, Value and Justification: The Foundations of Liberal Theory, Cambridge Studies in Philosophy, ed. Sydney Shoemaker (Cambridge: Cambridge University Press, 1990), 80-105.

${ }^{10}$ Olena V. Smyntyna, "Adaptation, Cultural", en Encyclopedia of Anthropology, ed. H. James Birx (California: Sage Publications, 2006), 1:17. 
permite ubicarnos en nuestro plano terrenal local, no siempre se extiende hasta el ámbito universal. Después de todo, ¿quién se detiene a pensar en qué situación se encuentra en el plano cósmico? Si sé ubicarme en una situación social, ¿dónde nos encontramos desde un ángulo universal? ¿Tiene sentido todo esto que hacemos?

La respuesta a estas preguntas define lo que conocemos como "cosmovisión", es decir, "la estructura profunda detrás de la cultura, que consiste de postulados, valores y compromisos, compartida por los miembros de un grupo humano o etnia". ${ }^{11}$ De esta manera, una cosmovisión involucra contenido comprensible en forma de conocimiento o creencias (postulados), valores que conforman los preceptos de conducta adoptados cotidianamente (valores), y compromisos que ligan a las personas a seres o entidades en un vínculo de lealtad (compromisos). Por lo general, la cosmovisión es aceptada inconscientemente, pero repercute invariablemente en la conducta. Incluso nosotros, en este mismo momento, mientras usted lee estas líneas y mientras yo las escribo, estamos comportándonos según nuestra cosmovisión, aunque nunca hayamos pensado sobre ella. En términos prácticos, si pienso que estoy en este universo como producto del azar y que, por lo tanto, el futuro es igual de oscuro e incierto (postulado), entonces puedo hacer de mi vida lo que me venga en gana (valores), y mi lealtad a las relaciones familiares o sociales no es más duradera que las interacciones de los simios en la naturaleza (compromisos). ¿Lo ve? Por alguna razón, alguien dijo que la conversión, entendida en términos bíblicos, ocurre en el nivel de la cosmovisión. Incluso Charles Kraft afirmó que "sin cambio de cosmovisión no hay conversión" ${ }^{12}$

Ahora bien, el valor universal de Daniel y Apocalipsis es precisamente este: presenta una cosmovisión divina. La cosmovisión apocalíptica asume que el tiempo en el que todas las cosas ocurren no es una simple secuencia de eventos, sino que todo se mueve hacia un fin u objetivo. Esta suprema "meta" de la

${ }^{11}$ Levi Decarvalho, "Aspectos Culturales de la Misión", en Misión global, ed. Levi DeCarvalho (Pasadena, California: Centro Latinoamericano para la Misión Mundial, 2006), 360. Énfasis añadido.

12Ibíd. 
historia, la cual "es la misma para el individuo que para el universo, puesto que Dios lo ha creado, es la salvación final, y todos los eventos son la historia de la salvación" ${ }^{13}$ Esta singular perspectiva filosófica de la historia transmitida por ambos libros, entretejiendo momentos históricos con la evidencia real de la intervención divina en los asuntos humanos, ${ }^{14}$ aporta un significado trascendente (1) al cosmos que, de otra manera, permanece en la incertidumbre de un futuro catastrófico; (2) a la vida humana, pues le muestra un derrotero histórico cuyo fin supremo salvífico es dirigido por Dios; y (3) a la iglesia, pues le indica su tiempo, su identidad y su deber. ${ }^{15}$ De este modo, en marcado contraste con el vacío existencial resultante de una perspectiva científica del fin, una visión apocalíptica de la historia nos señala enérgicamente: “Tú estás aquî". ${ }^{16}$ El tiempo en que vives tiene sentido en el contexto glorioso de la historia de la salvación. ¡Qué verdad más poderosa para transformar nuestro presente!

\section{DANIEL Y APOCALIPSIS: SU IMPORTANCIA PARA IGLESIA DEL SIGLO XXI}

El valor universal objetivo de Daniel y Apocalipsis nos conduce ahora a considerar su importancia subjetiva, es decir, de su relevancia para el lector. Para hacerlo, veremos en primer lugar su importancia para la iglesia. Hace casi tres milenios, el sabio Salomón, hablando del papel que la conducción divina por medio de la profecía había jugado en la preservación del orden y bienestar del pueblo hebreo, observó que sin la "revelación" (hạzôn $)^{17}$ divina el pueblo se “descontrola (yipāra')"18 (Pr 29:18). Mucho tiempo después, esta verdad no ha perdido su vigencia e importancia. El "control" provisto por Dios a través su revelación en todas las Escrituras debe considerarse al establecer la forma, el

\footnotetext{
${ }^{13}$ Jacob Taubes, Occidental Eschatology, trad. David Ratmoko (Standford: Standford University Press, 2009), 33. El énfasis está en el original.

${ }^{14}$ Merling Alomía, Daniel: El varón muy amado de Dios (Lima: Ediciones Theologika, 2010), 2.

${ }^{15}$ Frank B. Holbrook, ed., Symposium on Revelation: Introductory and Exegetical Studies - Book I (Silver Spring, MD: Biblical Research Institute, 1992), 175.

${ }^{16}$ Leslie N. Pollard, "Visions of Victory", en "What Are Human Beings That You Remember Them?", ed. Clinton Wahlen (Silver Spring, MD: Review and Herald, 2015), 309.

${ }^{17} \mathrm{~L}$. Koehler, W. Baumgartner y J. J. Stamm, The Hebrew and Aramaic lexicon of the Old Testament, trad. M. Richardson, CD-ROM (Leiden: Brill, 1994-1996, 1999), 302.

${ }^{18}$ Ibíd., 970.
} 
contenido y los límites de la doctrina y la misión adventistas. ${ }^{19}$ A continuación, analizaremos ese "control" tal como se revela en los libros de Daniel y Apocalipsis, notando su influencia en tres niveles: ¿Quiénes somos? (nivel existencial) ¿Qué debemos creer? (nivel doctrinal) ¿Qué debemos hacer? (nivel misionológico)

¿Quiénes somos? En el contexto religioso global posmoderno se ha llegado a afirmar que "la identidad humana y, especialmente la identidad espiritual o teológica es [...] algo que está en un constante proceso de llegar a ser en lugar de ser un estado fijo de $s e r^{\prime} .{ }^{20}$ Por lo tanto, "la reflexión teológica sobre la identidad debe reflejar la naturaleza plural de diversas realidades" ${ }^{21}$ Esta concepción relativa e indefinida de la identidad religiosa surge de los estudios sociológicos realizados el siglo pasado, en los cuales se intentó señalar que la noción de identidad era la responsable del aumento de la violencia y el abuso en diversas partes del mundo.22 Como consecuencia, en lugar de identidad, hoy se prefiere hablar de consideración por las diferencias del otro, multiculturalidad y diversidad. ${ }^{23}$ Frente a esta posición, podemos preguntarnos: si la identidad cristiana no debe ser definida por una verdad única, ni es la mejor ni la más adecuada expresión de la religión en general, entonces, ¿qué es? La respuesta a esta cuestión es de extrema importancia, pues provee el marco en el cual surge la doctrina y la práctica de la iglesia. La incertidumbre que reviste al concepto de identidad en la religión a nivel global es un claro indicio de la gran necesidad de establecerla sobre un paradigma de fundamentos sólidos. ${ }^{24}$

Ahora bien, la posición adventista sobre su propia identidad ha tenido históricamente como paradigma fundamental a las Sagradas Escrituras y, de

${ }^{19}$ Fernando Canale, "Sola Scriptura and Hermeneutics: Toward a Critical Assessment of the Methodological Ground of the Protestant Reformation", Andrews University Seminary Studies 50, no. 2 (2012): 179-205. En adelante AUSS.

${ }^{20}$ Sue Yore, "Theological Identity in Post-modernity through a Literary Lens", en Community Identity: Dynamics of Religion in Context, ed. Sebastian C. H. Kim y Pauline Kollontai (London: T\&T Clark, 2007), 13. Énfasis añadido.

${ }^{21}$ Ibíd.

${ }^{22}$ Jaco Kruger, "Christian Identity in an Age of Difference", en Christian Identity, ed. Eduardus Van der Borght, Studies in Reformed Theology 16 (Leiden: Brill, 2008), 119.

${ }^{23}$ Ibíd.

${ }^{24}$ Medi Ann Volpe, Rethinking Christian Identity: Doctrine and Discipleship, Challenges in Contemporary Theology (Oxford: Wiley-Blackwell, 2013), 3. 
manera particular, a las profecías de Daniel y Apocalipsis. ${ }^{25}$ Según Elena G. de White, ambos libros, cuyo contenido es de "suma importancia" 26 para la iglesia, "permanecen firmes" y describen "los grandes y solemnes acontecimientos que debemos reconocer en este momento cuando estamos en el mismo umbral de su cumplimiento" ${ }^{27}$ De esta manera, sobre el fundamento firme que Daniel y Apocalipsis establecen para interpretar los eventos a punto de cumplirse, surge la identidad del adventismo como la "iglesia remanente". De acuerdo con Apocalipsis, ella es identificada porque guarda "los mandamientos de Dios" (Ap 12:17), tiene "el testimonio de Jesús" (12:17), es un pueblo que posee "perseverancia" (hupomoné), tiene "la fe de Jesús" (14:12) y proclama el mensaje de los tres ángeles (14:6-12). ${ }^{28}$ Asimismo, por medio de la designación 'ereș haș̣ebî ("tierra gloriosa"; Dn 11:41), Daniel prevé en un contexto escatológico la permanencia del pueblo remanente de Dios, el cual experimenta la crisis final causada por la oposición de una confederación perversa originada por el rey del norte. ${ }^{29}$

Además, Daniel y Apocalipsis también proveen el marco temporal y el contenido del mensaje que identifica al remanente. ${ }^{30}$ En primer lugar, respecto a su aparición en el tiempo, los diversos períodos proféticos, tales como los 1260 días (Dn 7:25; 12:7; Ap 11:2, 3; 12:6; 13:5), los 1290 días (Dn 12:11) y los 1335 días (Dn 12:12), los cuales se extienden desde el año 508 y 538 d. C. hasta el año 1798

${ }^{25}$ Stefan Höschele, "The Remnant Concept in Early Adventism: From Apocalyptic Antisectarianism to an Eschatological Denominational Ecclesiology", AUSS 51, no. 2 (2013): 267300.

${ }^{26 E l e n a ~ G . ~ d e ~ W h i t e, ~ T h e ~ S p i r i t ~ o f ~ P r o p h e c y ~(1844), ~ 4: 211 ; ~ c f . ~ I b i ́ d ., ~ E l ~ C o n f l i c t o ~ d e ~ l o s ~ S i g l o s ~}$ (Miami, FL: Asociación Publicadora Interamericana, 2007), 340.

${ }^{27}$ Elena G. de White, Mensajes Selectos (Nampa, ID: Pacific Press, 1967), 2:124.

${ }^{28}$ Gerhard Pfandl, "Identifying Marks of the End-Time Remnant in the Book of Revelation", en Toward a Theology of the Remnant: An Adventist Ecclesiological Perspective, ed. Ángel Manuel Rodríguez, Studies in Adventist Ecclesiology 1 (Silver Spring, MD: Biblical Research Institute, 2009), 140.

${ }^{29}$ Carlos E. Mora, "The Remnant in Daniel 11:40-45", en "The End from the Beginning": Festschrift Honoring Merling Alomía, ed. Benjamín Rojas, Teófilo Correa, Lael Caesar y Joel Turpo (Lima: Editorial Universidad Peruana Unión, 2015), 249-264.

${ }^{30}$ Alberto R. Timm, "The Prophetic Nature of Adventism", en The Word: Searching, Living, Teaching (Silver Spring, MD: Review and Herald, 2015), 229-233, 237-242. 
d. C., ${ }^{31}$ establecen el comienzo de lo que conocemos como "tiempo del fin" (Mt 24:29-31; Lc 21:25-28; Ap 6:12-13). Por otro lado, a partir de Daniel 8:14 y 9:24-27 se establece el período de 2300 días-años, el cual se extiende desde 457 a. C. hasta el año 1844 d. C. ${ }^{32}$ El punto de unión crucial entre estos períodos de Daniel y los descritos en Apocalipsis, se encuentra en el capítulo 10 de este último libro. En el versículo 6 se declara: jrónos oukéti éstai ("tiempo no será más”; Ap 10:6). Según Beale, esta declaración "no debe ser entendida en el sentido filosófico técnico de que al final de la historia habrá una abolición del tiempo, el cual será reemplazado por la atemporalidad. La idea aquí es que hay un tiempo predeterminado en el futuro cuando los propósitos de Dios para la historia se cumplirán". ${ }^{33}$ En armonía con esta observación, la iglesia adventista considera que ese tiempo predeterminado para el cumplimiento de los propósitos divinos se refiere al fin de la profecía de los 2300 días-años, ${ }^{34}$ cuyo cumplimiento en Apocalipsis involucra una desilusión amarga (Ap 10:9-10) y una declaración de misión consistente en "profetizar" otra vez (10:11), es decir, proclamar la revelación divina, dar a conocer lo que había estado oculto. ${ }^{35}$

Respecto al contenido de esta proclamación que identifica al remanente, ya en 1884, Elena G. de White había escrito: “El pasaje bíblico que más que ninguno había sido el fundamento y el pilar central de la fe adventista era la declaración: 'Hasta dos mil y trescientas tardes y mañanas; entonces será purificado el santuario' (Dn 8:14)". ${ }^{36}$ Al fin de este período profético “Dios levantó el movimiento Adventista del Séptimo Día para restaurar la verdad bíblica del

\footnotetext{
${ }^{31}$ Para los fundamentos bíblicos del principio "día por año", véase Alberto R. Timm, "Miniature Symbolization and the Year-Day Principle of Prophetic Interpretation", AUSS 42, no. 1 (2004): 149-167; y Gerhard Pfandl, "El principio de 'día por año'", en este volumen.

${ }^{32} \mathrm{Timm}$, "The Prophetic Nature of Adventism", 233-234.

${ }^{33 G r e g o r y ~ K . ~ B e a l e, ~ T h e ~ B o o k ~ o f ~ R e v e l a t i o n: ~ A ~ C o m m e n t a r y ~ o n ~ t h e ~ G r e e k ~ T e x t, ~ N e w ~}$ International Greek Testament Commentary (Grand Rapids, MI: Eerdmans, 1999), 539.

${ }^{34}$ Francis D. Nichol, ed., Comentario Bíblico Adventista del Séptimo Día, trad. Nancy W. de Vyhmeister y Víctor E. Ampuero Matta (Buenos Aires: Asociación Casa Editora Sudamericana, 1996), 7:813.

35Walter Bauer, A Greek-English Lexicon of the New Testament and Other Early Christian Literature, ed. William F. Arndt, F. Wilbur Gingrich, Frederick W. Danker (Chicago: University of Chicago Press, 1958), s. v. "профртвن் ", 723; Timm, “The Prophetic Nature of Adventism", 234.

36Elena G. de White, The Spirit of Prophecy (1884), 4:258; cf. Ibíd., El Conflicto de los Siglos, 405.
} 
santuario". ${ }^{37}$ Como ha notado Timm, tanto el mensaje de la purificación del santuario en Daniel 8:14 como el mensaje de los tres ángeles de Apocalipsis 14:612 fueron fundamentales para el desarrollo de la identidad doctrinal adventista. ${ }^{38}$ En este último pasaje, la restauración de la verdad vaticinada por Daniel 8:14 es acompañada por una exhortación al mundo entero a responder al sacrificio de Cristo con obediencia a los mandamientos de Dios y con la verdadera adoración al Creador (Ap 14:6-7), por un llamado al verdadero pueblo de Dios a salir de Babilonia para que no sufran las plagas preparadas como juicio por su iniquidad (14:8) y, finalmente, por una advertencia a todo aquel que reciba la marca de la bestia a fin de que evite beber del vino puro de la ira de Dios (14:10).

Con la finalidad de impulsar el mensaje especial de la iglesia remanente, surge un tercer componente identificador de la misma: la asistencia divina a través del don de profecía. Nuevamente, el texto clave de esta manifestación especial del Espíritu en el tiempo del fin se halla en la profecía apocalíptica. La mención que Apocalipsis 12:17 hace del "testimonio de Jesús" (tēn martyrían Iēsou), explicado como "el espíritu de profecía" (to pneuma tēs profēteías) en 12:19, deja claro que, "en el tiempo del fin, la iglesia tendrá la orientación profética como en el tiempo de Juan". ${ }^{39}$ Con la implementación del don de profecía, la identidad de la iglesia remanente queda claramente definida en términos de su aparición en el tiempo, su mensaje especial y su orientación profética. Como ya habrá notado el lector, en cada una de estos aspectos de su historia, Daniel y Apocalipsis jugaron un papel prominente. $\mathrm{Su}$ influencia es resumida de esta manera por LaRondelle:

El punto central de actividad del despertar adventista, tanto antes como después de 1844, estuvo en las profecías del tiempo del fin de Daniel y Apocalipsis. Fue a la luz de esas profecías que los pioneros de la IASD

37Timm, "The Prophetic Nature of Adventism", 239.

${ }^{38}$ Alberto R. Timm, El Santuario y el Mensaje de los Tres Ángeles: Factores Integradores en el Desarrollo de las Doctrinas de la Iglesia Adventista del Séptimo Día (Lima: Editorial Imprenta Unión, 2004), 1.

${ }^{39}$ Ranko Stefanovic, "The 'Spirit of Prophecy' in the Revelation of John", en The Gift of Prophecy in Scripture and History, ed. Alberto R. Timm y Dwain N. Esmond (Silver Spring, MD: Review and Herald, 2015), 199. 
comenzaron a desarrollar la comprensión teológica de sí mismos como un nuevo movimiento en la historia cristiana. ${ }^{40}$

La construcción de una identidad provee dirección y propósito a la iglesia. De esta razón eclesiológica que justifica el estudio ferviente de Daniel y Apocalipsis se desprenden las otras dos: la razón doctrinal-teológica y la razón misionológica. La primera responde a la pregunta, ¿en qué debemos creer? En relación a esta cuestión, la siguiente afirmación de Elena G. de White no deja de impactarme:

Toda experiencia genuina en materia de doctrinas religiosas llevará la impronta de Jehová. Todos deben ver la necesidad de comprender la verdad por sí mismos, individualmente. Debemos comprender las doctrinas que hemos estado estudiando cuidadosamente y con oración. Se me ha revelado que hay entre nuestros hermanos una gran falta de conocimiento con respecto al surgimiento y progreso del mensaje del tercer ángel. Existe una gran necesidad de investigar el libro de Daniel y el Apocalipsis, y aprender los textos cuidadosamente, para que sepamos lo que está escrito. ${ }^{41}$

El estudio de las doctrinas, a menudo considerado infructífero en la vida práctica y sacrificado "en aras de" la misión, se muestra en la cita anterior como una "gran necesidad", principalmente en relación a la verdad presente tal como se revela en Daniel y Apocalipsis. Partiendo de nuestra identidad como iglesia remanente, ¿cómo es posible proclamar aquel mensaje especial sin apropiarse de su significado antes? Hoy más que nunca es necesario ahondar en el conocimiento de "lo que está escrito". En notable contraste con la idea de que las doctrinas pertenecen al ámbito teórico abstracto de la religión relegado a los

${ }^{40}$ Hans K. LaRondelle, "The Remnant and the Three Angels' Messages", en Handbook of Seventh-Day Adventist Theology, ed. Raoul Dederen, Commentary Reference Series 12 (Hagerstown, MD: Review and Herald Publishing Association, 2001), 857. Habiendo puesto de relieve el aporte de Daniel y Apocalipsis a la identidad adventista, cabe mencionar ahora que la iglesia adventista del séptimo día no se identifica como la iglesia remanente apoyándose únicamente en ambos libros o en la enseñanza de ciertas doctrinas cristianas aisladas como la del séptimo día sábado, la manifestación del don de profecía, el santuario o los mensajes de los tres ángeles. El fundamento de su identidad es, en última instancia, solo las Escrituras en la totalidad de su contenido y la guía hermenéutica que estas proveen. Fernando Canale, "On Being the Remnant", Journal of the Adventist Theological Society 24, no. 1 (2013): 170. Een adelante JATS.

41Elena G. de White, El Evangelismo (Miami, FL: Asociación Publicadora Interamericana, 1994), 266. 
teólogos, Elena de White dice lo siguiente sobre el estudio de las Escrituras, particularmente en lo que atañe a Daniel y Apocalipsis:

Los que comen la carne y beben la sangre del Hijo de Dios sacarán de los libros de Daniel y el Apocalipsis la verdad inspirada por el Espíritu Santo. Pondrán en marcha fuerzas que no puedan ser reprimidas. Los labios de los niños se abrirán para proclamar los misterios que han estado ocultos. ${ }^{42}$

El libro de Apocalipsis, junto con el de Daniel, merece estudio especial. Todo maestro temeroso de Dios debe considerar cómo comprender y presentar más claramente el evangelio que nuestro Salvador en persona dio a conocer a su siervo Juan: "La revelación de Jesucristo, que Dios le dio, para manifestar a sus siervos las cosas que deben suceder pronto. ${ }^{43}$

En estas declaraciones encontramos la razón misionológica resultante de la comprensión de nuestra identidad. ${ }^{44}$ Tal razón responde a la pregunta, ¿qué debemos hacer? Como puede notarse, para Elena G. de White el estudio de Daniel y Apocalipsis guiado por el Espíritu Santo pondrá en labios humildes un "mensaje que despierte a las iglesias". ${ }^{45}$ Mediante la comprensión de la verdad revelada en ambos libros, se provee a la iglesia de una fuerza imposible de reprimir, a tal punto que hasta los niños proclaman "los misterios que han estado ocultos", es decir, cumplen la misión de "profetizar" otra vez (Ap 10:11). Ya sea por la página impresa ${ }^{46}$ o por la predicación audible, "Daniel y el Apocalipsis deben recibir atención como nunca antes en la historia de nuestra obra". ${ }^{47}$ De nuestra comprensión de identidad brota nuestro compromiso con la verdad

${ }^{42}$ Elena G. de White, Maranata: El Señor Viene (Miami, FL: Asociación Publicadora Interamericana, 2008), 31.

${ }^{43}$ Elena G. de White, La Educación (Miami, FL: Asociación Publicadora Interamericana, 2009), 171.

${ }^{44}$ En cuanto a misionología en la literatura apocalíptica bíblica, el libro de Daniel ha sido investigado para extraer principios de evangelismo intercultural en Sung Ik Kim, "Proclamation in Cross-Cultural Context: Missiological Implications of the Book of Daniel" (PhD diss., Andrews University, 2005).

${ }^{45}$ Elena G. de White, Testimonios para los Ministros (Buenos Aires: Asociación Casa Editora Sudamericana, 1979), 117.

46Elena G. de White habló de la importancia de la página impresa en la divulgación del mensaje de Daniel y Apocalipsis en esta cita: "Se me ha instruido en el sentido de que las profecías de Daniel y el Apocalipsis deben imprimirse en libros pequeños, con las explicaciones necesarias, y deben enviarse al mundo entero. Nuestros mismos hermanos necesitan que se les presente la luz con más claridad". Véase Elena G. de White, Testimonios para los Ministros (Buenos Aires: Asociación Casa Editora Sudamericana, 1979), 117.

47Elena G. de White, Testimonios para los Ministros (Buenos Aires: Asociación Casa Editora Sudamericana, 1979), 112. 
presente revelada de forma especial en Daniel y Apocalipsis. De nuestro compromiso con dicha verdad, surge, por obra del Espíritu, el poder para cumplir la misión. Así, identidad, doctrina y misión, elementos fundamentales de nuestra existencia como iglesia remanente, son encapsuladas por las profecías de Daniel y Apocalipsis. Tal es la razón particular de su importancia. ¡Hermanos, no descuidemos estos asuntos "de importancia infinita en estos últimos días"! 48

\section{DANIEL Y APOCALIPSIS: SU IMPORTANCIA PARA NOSOTROS}

En el plano subjetivo individual, el valor de un objeto cambia de acuerdo a quién mira ese objeto. Si ponemos frente a un niño muy pequeño 1 gran caramelo y un billete de 200 soles pidiéndole que elija entre ambos, lo más seguro es que elegirá el caramelo por considerarlo de mayor valor para él. Si, por el contrario, le pedimos a un adulto que haga la misma elección, indudablemente elegirá el billete porque no le interesa un insignificante caramelo. Si a nosotros, los autores, se nos pidiera elegir entre una prenda de vestir de una exclusiva marca o un buen libro, decididamente elegiríamos el libro porque es lo que a nosotros nos interesa. Todos elegimos las cosas de acuerdo a nuestro interés en ellas. Aunque el valor de Daniel y Apocalipsis por sí mismos es innegable, puesto que son parte de la revelación divina, ¿por qué debería interesarle a usted (y a nosotros) leerlos? ¿en qué cambiaría nuestra vida y la de nuestra familia aquí y ahora?

Para percibir el impacto de Daniel y Apocalipsis en nuestra vida cotidiana, en primer lugar, definamos la forma en que la profecía apocalíptica, al vincular el pasado, el presente y el futuro, determina el significado de la vida. Tanto Daniel como Apocalipsis tienen una porción histórica (Dn 1-6; Ap 1-12) y una porción escatológica (Dn 7-12; Ap 13-22). Este rasgo básico de sus estructuras literarias nos dice desde el mismo principio que ambos presentan una conexión muy estrecha entre la historia y el futuro. Por ejemplo, tanto el profeta Daniel y como el apóstol Juan experimentaban la cautividad en el momento en que recibieron la revelación divina: el primero, en Babilonia; el segundo, en Patmos.

${ }^{48}$ Elena G. de White, El Cristo Triunfante (Miami, FL: Asociación Publicadora Interamericana, 1999), 336. 
Curiosamente, sus libros también tienen que ver parcialmente con tiempos en los que el pueblo de Dios estaba bajo persecución u opresión. De este modo, dicho contexto histórico es el punto de partida de los mensajes escatológicos que brindaron aliento al pueblo de Dios cuando este fue perseguido a lo largo de la historia y cuando lo sea en el tiempo del fin.

Asimismo, el libro de Apocalipsis tiene rasgos claros de haber sido dirigido a cierta audiencia específica, en un tiempo y lugar específicos $(1: 4 ; 22: 16) .{ }^{49}$ De manera similar, Daniel empieza con el reporte histórico de una derrota del pueblo de Judá y el triunfo de sus enemigos (Dn 1:1-2). Aunque ambos datos históricos nos remiten a un tiempo y espacio concretos, al mismo tiempo nos proyectan hacia la universalidad del mensaje contenido en los libros en su conjunto, de modo que el mensaje a las siete iglesias de Asia se dirigen a todo aquel "que tiene oído" $(2: 7,11,17,29 ; 3: 6,13,22)$, mientras que la conquista de Judá a manos de Nabucodonosor llega a ser "un capítulo más de la enemistad de 'Babel' contra los planes definidos de Dios para con su pueblo'50 y, por consiguiente, se convierte en "un conflicto universal". ${ }^{51}$ De este modo, queda claro que la escatología apocalíptica se extiende desde la historia en el pasado hasta su manifestación final o consumación en el futuro. En ese sentido, el informe de Daniel y Apocalipsis sobre nuestro mundo “es tridimensional, con un pasado, presente y futuro". 52

Entendiendo esto, ¿cuál es, entonces, la importancia primordial del estudio de Daniel y Apocalipsis? Al unir los hilos del pasado, el presente y el futuro, el estudio de estos libros es capaz de redefinir completamente nuestra percepción de la vida y de todos los componentes de la misma. Esta redefinición, que bien podemos llamar cambio de cosmovisión, se manifiesta en 1) nuestro concepto de la historia y su objetivo, 2) en nuestra visión del centro de la existencia, 3) en 13.

${ }^{49}$ Jon Paulien, Seven Keys: Unlocking the Secrets of Revelation (Nampa, ID: Pacific Press, 2009),

50Merling Alomía, Daniel: El profeta mesiánico, vol. 2 (Lima: Ediciones Theologika, 2010), 11.

${ }^{51}$ Jacques B. Doukhan, Secretos de Daniel (Florida: Asociación Publicadora Interamericana, 2008), 13.

52Norman R. Gulley, Systematic Theology: The Church and the Last Things (Berrien Springs, MI: Andrews University Press, 2016), 16-17. 
nuestro sentido de identidad y misión, 4) y en nuestro concepto del fin de la historia.

Al estudiar Daniel y Apocalipsis nuestro concepto de historia se centra en la soberanía suprema de Dios. ${ }^{53}$ Cuando Daniel empieza su libro reportando la derrota del pueblo del pacto, surge la pregunta, ¿podía el Dios de Israel ser llevado cautivo a una tierra extranjera? La respuesta es "no". Dios, en su soberanía, "entregó" (wayyitèn) a su pueblo a la cautividad.54 Nuevos desafíos a la soberanía y el poder supremo de Dios aparecen a lo largo de ambos libros (Dn 3:15; Ap 13:4), haciéndose más intenso en la descripción de un poder que habla palabras arrogantes contra Dios, que ostenta una hegemonía durante 1260 años, y que persigue a los santos (Dn 7:6-8, 19-23, 24-25; Ap 12:13-16). A pesar de todo lo que hacen las fuerzas del mal contra Dios y su pueblo, ${ }^{55}$ se presenta con certeza categórica que Dios es Todopoderoso (1:8) y que gobierna desde su trono celestial (4 y 5), es decir, su Santuario, lugar desde el que trata el problema del mal en el universo y emite sus juicios (Dn 7, 8, 9; Ap 15:5-8). ${ }^{56}$ La consecuencia de la realidad de la soberanía de Dios en el presente es: Dios tiene el control de la historia, por tanto, su vida tiene propósito.

Al estudiar Daniel y Apocalipsis renovamos nuestra visión del centro de la existencia. Ambos libros hablan del Cristo exaltado (Dn 7:13-14; Ap 1:10-20), ${ }^{57}$ mencionando directamente su nombre (Ap 1:1-9; 12:17; 22:16-21) o mediante otras designaciones, tales como el Hijo del hombre (Ap 1:13), el León de la tribu de Judá (Ap 5:5), el Cordero (Ap 5:6, 8, 12), el Hijo varón (Ap 12:5), y el Verbo de Dios (Ap 19:13). En armonía con el mensaje de la soberanía de Dios, el Hijo es

53JulioValdeón, “El Mundo Cristiano (Antiguo y Medieval)”, en Filosofía de la Historia, Enciclopedia Iberoamericana de Filosofía, ed. Manuel Reyes Mate (Madrid: Editorial Trotta, 2013), 47-64.

54Zdravko Stefanovic, Daniel: Wisdom to the Wise (Nampa, ID: Pacific Press, 2007), 32.

55Por ejemplo, ambos libros incluyen un mandato a adorar una imagen cuyo incumplimiento es condenado con la muerte (Dn 3:1-28; Ap 13:14-15). Asimismo, con vívido lenguaje, Apocalipsis muestra a los poderes del mal oponiéndose a Dios y sus santos (11:1914:20).

${ }^{56}$ Alomía, Daniel: el varón muy amado de Dios, 214-220.

57Ekkehardt Mueller, "Christological Concepts in the Book of Revelation - Part 1: Jesus in the Apocalypse", JATS 21, no. 1-2 (2010): 276-305. 
mostrado como igualmente divino (Ap 1:17; 5:13, 14). ${ }^{58}$ Además, tanto las profecías de Daniel como las de Apocalipsis están vinculadas con la encarnación, muerte, resurrección, ascensión y el reino venidero del Mesías (Ap 1:5; 5:6; 12:5). En relación a nosotros, se brinda la seguridad de que con la sangre del Cordero se lavan nuestros pecados (Ap 1:5 $)^{59}$ y recibimos poder para vencer el mal y las tentaciones de Satanás (Ap 12:11). Siendo así, el vencedor definitivo en la gran controversia es Miguel, el Mesías y, por consiguiente, (Ap 12:3) la victoria en el tiempo del fin es posible únicamente por medio de Él (Ap 17:14; 19:11-21). En el presente, el mensaje de la centralidad de Cristo en el despliegue de la historia es: el sentido de su vida se encuentra en conocer a Cristo Jesús.

Al estudiar Daniel y Apocalipsis también obtenemos nuestro verdadero sentido de identidad y misión. Apocalipsis muestra mensajes directos a la iglesia militante (1:10-3:22) y el futuro glorioso que le espera (21:5-22:5). En el contexto del tiempo del fin, el pueblo de Dios aparece en forma simbólica como los cientos cuarenta y cuatro mil (7:4-8), la gran multitud (7:9-12), el remanente (12:17), los santos (14:12), y los "llamados, elegidos y fieles" seguidores del Cordero (17:4). Además de trazar su identidad, Daniel y Apocalipsis establecen la misión de la iglesia y el contenido de su proclamación, el cual es un triple mensaje escatológico especial de adoración (Dn 3), de juicio (Dn 7 y 8) y de lealtad (Dn 6; Ap 14:6-11). ${ }^{60}$ La consecuencia del sentido de identidad y misión eclesiológicas en el presente es: usted puede ser parte de la comunidad que Dios viene a salvar, no está solo.

Por último, al estudiar Daniel y Apocalipsis transformamos nuestra visión del fin de la historia. La continua obra de Dios para efectuar la salvación en la historia se despliega en las series histórico-proféticas de Apocalipsis (Ap 4:1-8:1; 8:2-11:18). ${ }^{61}$ Esta historia redentora encuentra su clímax en el juicio final de Dios, el cual está rodeado de los eventos de la segunda venida de Cristo, el milenio y

${ }^{58}$ Ekkehardt Mueller, “Christological Concepts in the Book of Revelation-Part 2: Christ's Divinity", JATS 22, no. 1 (2011): 66-83.

${ }^{59}$ Ekkehardt Mueller, "Christological Concepts in the Book of Revelation - Part 3: The Lamb Christology", JATS 22, no. 2 (2011): 42-66.

60Alomía, Daniel: El profeta mesiánico, 223-226.

61Holbrook, 177. 
el juicio ante el gran trono blanco (Ap 19:1-21:4). Asimismo, el drama de la redención es descrito a partir de un gran conflicto entre el bien y el mal originado en el cielo (Ap 12:7-9)62 y desarrollado en la experiencia real del pueblo de Dios en la tierra (Ap 2:9, 10, 24; 3:9; 12:10-14). Aunque la batalla ya ha sido ganada con la victoria de Cristo (Ap 12:10,11), esta solo tendrá su consumación absoluta y definitiva al final de los mil años (Ap 20:7-10). En concordancia con estas predicciones, Daniel testifica de la certeza de la restauración de Judá y de Jerusalén (Dn 9:25), y del establecimiento del reino de Dios (Dn 2:44). Finalmente, el último y más tenebroso enemigo de la humanidad, la muerte, también es vencido por la certeza de la resurrección (Dn 12:1-2). Así pues, la consecuencia de nuestra visión renovada del fin del mundo en el presente es: Jesús viene por usted. Prepárese para la felicidad eterna.

\section{CONCLUSIÓN}

Desde una perspectiva objetiva universal, Daniel y Apocalipsis contienen una cosmovisión que interpreta la historia como siendo dirigida por Dios y, en consecuencia, como una historia con sentido y significado que va más allá de lo que experimentamos en esta vida. Desde una perspectiva subjetiva colectiva, el estudio de estos libros define singularmente la identidad, la doctrina y la misión de la iglesia. Desde una perspectiva subjetiva individual, Daniel y Apocalipsis contienen un mensaje capaz de cambiar la forma en que usted aprecia su existencia, el centro de su vida, su misión vital y su perspectiva del futuro, transformando su vida y la mía. Estas líneas de influencia presentes en ambos libros apocalípticos justifican sobradamente las horas invertidas en su estudio. No obstante, en medio de esta justificación lógica para su estudio, no debe perderse de vista la naturaleza profundamente espiritual de Daniel y Apocalipsis. El primer libro, presentando gloriosamente al bar 'ěnāš ('hijo de hombre', Dn 7:13); y el segundo, siendo el apokálypsis Iēsou Jristou ('revelación de Jesucristo', Ap 1:1), presentan al personaje clave de la historia y el único medio Grabiner, "The Cosmic Conflict: Revelation's Undercurrent", JATS 26, no. 1 (2015): 38-56. 
por el que todas las maravillas del futuro previsto por las profecías alcanzarán su cumplimiento: Jesucristo. Ambos libros nos dirigen a Él en medio de la vertiginosa sucesión de acontecimientos de nuestro universo para darnos la certeza de que nuestro futuro está en manos de quien es nuestro Padre (Is 9:6), Amigo (Juan 15:15), Hermano (Heb 2:11), Salvador (Hch 4:12) y Rey (Ap 19:16).

Por esta razón, aaunque hayamos heredado mucho de Daniel y Apocalipsis en lo que a doctrina se refiere, la orden de Jesucristo demuestra que jamás agotaremos su significado, pues este continúa más vigente que nunca: “el que lee, entienda" (ho anaginốskōn noeítō; Mt 24:15). Es decir, la iglesia que lee la profecía apocalíptica, interprétela y aumente su sabiduría. ${ }^{63}$ Parte de nuestro deber presente, por lo tanto, es poner en práctica “un estudio mucho más detenido de la Palabra de Dios", 64 especialmente en lo que se refiere a Daniel y Apocalipsis. Cuando son considerados con sencillez de corazón, dependiendo de Aquel que nos ha dado a "conocer los misterios del reino de los cielos" (Mt 13:11), ambos libros proclaman "bienaventurado" ('ašrê, Dn 12:12), el que lee y los que oyen las palabras de esta profecía, y guardan las cosas en ella escritas, porque el tiempo está cerca” (Ap 22:7). ¡En nuestro futuro sí existe un gozo en la gloria!

${ }^{63}$ Grant R. Osborne, Matthew, Zondervan Exegetical Commentary on the New Testament (Grand Rapids, MI: Zondervan, 2010), 1:884.

64Elena G. de White, Testimonios para los Ministros (Buenos Aires: Asociación Casa Editora Sudamericana, 1979), 112. 